\title{
Gtautb’\& $\mathfrak{R} \mathfrak{m m e n t a r}$
}

stim

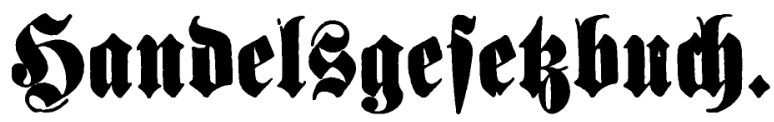

\section{Adhte Auflage}

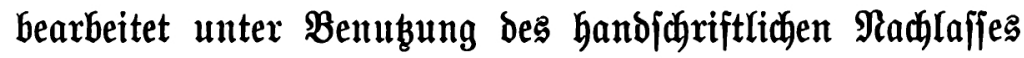

bon

\section{Geinrid fïnige, Dr. Io/ef Gtranz, Albert Minurer,

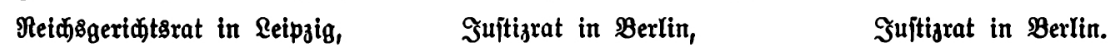

\section{3weiter Banb.}

(Buch) 3: Scandelägefłäätte.)

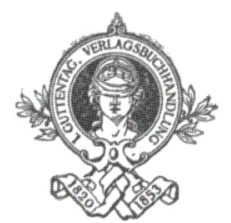

Berlin 1907.

ร. (B) $\mathfrak{u} \mathfrak{t} \mathfrak{e} \mathfrak{n} \mathfrak{a} \mathfrak{b}, \mathfrak{B} \mathfrak{e} \mathfrak{l} \mathfrak{a} \mathfrak{g}$

B. $\mathfrak{m}$. b. $\mathfrak{\$}$. 
